Research Article

\title{
Mechanical Properties and Failure Behavior of Composite Samples
}

\author{
Hongwei Zhang, Zhijun Wan ${ }^{(D)}$, Yuan Zhang ${ }^{D}$, and Dong Wu \\ Key Laboratory of Deep Coal Resource Mining (CUMT), Ministry of Education of China, School of Mines, \\ China University of Mining \& Technology, Xuzhou 221116, China \\ Correspondence should be addressed to Zhijun Wan; zhjwan@cumt.edu.cn
}

Received 18 April 2018; Revised 7 August 2018; Accepted 19 August 2018; Published 11 October 2018

Academic Editor: Dimitrios E. Manolakos

Copyright (c) 2018 Hongwei Zhang et al. This is an open access article distributed under the Creative Commons Attribution License, which permits unrestricted use, distribution, and reproduction in any medium, provided the original work is properly cited.

\begin{abstract}
In underground coal mining systems, the occurrences of coal burst hazards and pillar failures relate not only to the condition of stress distribution but also the geometry of roof-coal-floor structures. To study the failure response of these structures, the rockcoal-rock (RCR) sample, in which a coal component is sandwiched between rocks, is always employed as the experimental subject. In this study, the effect of height ratio (a ratio represents the height percentage of coal component in an RCR sample) on the mechanical properties and deformation behavior of RCR samples was numerically investigated by using the distinct element model (DEM). The results reveal the following. (1) The uniaxial compression strength (UCS) of the RCR sample decreases with increasing height ratio as an inverse proportional function. (2) With increasing height ratio, the elastic modulus of the RCR sample decreases exponentially, while the postpeak modulus is strengthened in an inverse proportional manner. (3) Microcracking activity of the RCR sample is different from that of the pure sample during loading. Specifically, a reactive period always occurs after the quiet and active periods in the RCR sample. (4) The RCR sample fails in a progressive manner, in which cracking bands develop preferentially in coal and then extend to rocks. Expectably, the mechanical properties and failure behavior of RCR samples are height ratio dependent, which may contribute to predicting the hazard of coal bursts and estimating the failure of rock-coal-floor structures.
\end{abstract}

\section{Introduction}

Coal bursts occur frequently in underground coal mining systems, causing fatal injury and facility damage [1-3]. Therein, coal pillar bursts refer to failures of roof-pillar-floor systems that have been a significant safety concern in deep coal mines (Figures 1(a-1) and 1(b-1)) [4-7]. Since coal seam is sandwiched between the roof and floor strata, the destruction of pillar is influenced not only by the condition of stress distribution but also the geometry of roof and floor (Figures 1(a-2), 1(a-3), 1(b-2), and 1(b-3)) [8]. Therefore, understanding the mechanical properties and failure mechanisms of roof-pillar-floor structures under variable composite geometries is significantly important regarding safety mining.

In experimental scale modelling, pure coal and pure rock samples are always employed to conduct uniaxial compression tests [9-11]. However, the shortcoming is that the pure samples cannot accurately reflect the overall mechanical properties of roof-pillar-floor structures. Thus, two types of composite cylindrical samples were simplified to conduct laboratory and numerical investigations. The first is rock-coal (RC) type, in which roof and coal components are considered (Figure 1(c-1)) [12-14]; another is rock-coal-rock (RCR) type, where the coal is sandwiched between roof (rock) and floor (rock) components (Figure 1(c-2)) [15-17]. Geologically, coal seams and the surrounding strata may vary in thickness, which in turn indicates that the roof-pillar-floor structures may differ in physical geometry. In this study, the physical geometry refers to the height percentage $\left(h_{r}\right)$ of the coal component in a composite sample.

To date, numerous attempts have been made to study the mechanical properties and deformation behavior of 
composite samples under uniaxial and triaxial compression conditions. In these studies, the most height ratios were between $40 \%$ and $60 \%$, and the results show the following. (1) The uniaxial compression strength (UCS) of the composite sample depends mostly on the coal component [12]. (2) A higher UCS of rock component always implies a greater UCS, and the RCR sample with a lower height ratio tends to burst easier [18]. (3) Most failure modes of composite samples are conjugate X-shaped shearing failures $[12,13,16]$. Briefly, these foregoing investigations demonstrated that the UCS and failure behavior of composite samples are material properties dependent. However, these studies have been mainly concentrated on either the effect of material property or the damage of coal $[19,20]$.

In the aspect of geometrical effect, some studies investigated the failure response of composite rocks with different composite types (e.g., rock-coal, rock-rock-coal, and rock-coal-rock) [21], with different geometrical sizes [22] and with different inclined angles [23]. Interestingly, Chen et al. [14] found that the UCS of the RC sample decreases with increasing height ratio. Furthermore, a lower height ratio of the composite sample always implies a greater rock burst accident [24]. These studies contribute to our knowledge about the geometrical influence on the mechanical properties of composite samples. However, the relationship between height ratio and UCS of the RCR sample is not fully understood due to prior inadequate considerations of roof-coal-floor geometry. In addition, limited effort has been applied to determine the influence of the height ratio on the deformation evolution of RCR samples under uniaxial compressive loading. Therefore, in addition to the factors such as the physical properties of coal and rock components, it is also a significant issue to consider the height ratio of the RCR sample.

Apart from the mechanical properties and failure behavior of composite structures, acoustic emission (AE) is often a concern because related dynamical effects may lead to great failure and pillar damage in underground mining systems $[25,26]$. Previous research has described the effect of the loading rate on the microcracking activities of RC and RCR samples [15, 27] but did not deal with the influence of the height ratio on the microcracking evolution of composite samples, which is a key issue to be investigated in this work.

This paper aims to study the effect of the height ratio on the mechanical properties and deformation evolution of RCR samples by conducting numerical simulation tests. Furthermore, by considering time-dependent cracks of the RCR sample, the microcracking characteristics in the deformation process of the RCR sample were simultaneously studied. In the following, the details of the methodology and results and discussion are explained.

\section{Numerical Methods and Materials}

The particle flow code in 2 or 3 dimensions (PFC2D (3D)) models the movement and interaction of circular (2D) or spherical (3D) particles using the DEM. It is possible for the blocks to break because they are composed of bonded particles [28, 29]. This software employs a DEM algorithm, and the DEM method iteratively solves Newton's second law of motion for an assembly of particles with a predefined contact bond model applied at the grain-grain contacts. The $\mathrm{AE}$ monitoring technology in discrete element modelling (DEM) is particularly suitable for studying the microcracking activities of samples.

2.1. Contact Bond Model in PFC. Two bonding behaviors are embodied in the contact-bond model (CBM) and parallelbond model (PBM) (Figures 2(a) and 2(b)) [30], both of which can be envisioned as a kind of glue joining two neighboring particles. A contact bond also can be envisioned as a pair of elastic springs with constant normal and shear stiffness acting at a contact point. The two springs located between two adjacent particles have specified shear and normal strengths and control the micromechanical behavior of a contact bond.

The intrinsic difference between CBM and PBM is that the CBM (Figure 2(a)) can only transmit forces acting at the contact point, while the PBM (Figure 2(b)) can transmit both forces and moments between particles. Moreover, bond breakage in PBM immediately results in stiffness reduction since stiffness is contributed by both contact and bond stiffness (Figure 2(d)) [30]. In PFC, rock can be represented as a heterogeneous material composed of cemented grains. A PBM provides the mechanical behavior of a cement-like material substance between two contacting particles, and the PBM has been widely employed in estimating the mechanical behavior of rocks [31, 32]. Therefore, in this research, we chose the PBM to carry out the numerical simulations.

2.2. Numerical Samples and Calibrations. The RCR samples were composed of sandstone and coal (Figure 3(a)), and nine samples with height ratios ranging from $0 \%$ to $100 \%$ were generated for uniaxial compression tests (Figure 3(b)). It is clear that samples with height ratios of $0 \%$ and $100 \%$ are pure sandstone and pure coal samples, respectively.

According to the ISRM standard [33], the dimension of a sample that undergoes uniaxial compression is $50 \mathrm{~mm}$ in width and $100 \mathrm{~mm}$ in height. In this study, each RCR sample $(\varphi 50 \mathrm{~mm} \times 100 \mathrm{~mm})$ is discretized into 6673 particles, and the particle size (i.e., diameter) followed a uniform distribution ranging from $0.35 \mathrm{~mm}$ to $0.58 \mathrm{~mm}$ [34]. The interparticle friction for particle is 0.577 , and the normal-toshear stiffness ratio is set as 2.5 for both rock and coal particles. The average unit weights of sandstone and coal are $2600 \mathrm{~kg} / \mathrm{m}^{3}$ and $1800 \mathrm{~kg} / \mathrm{m}^{3}$, respectively. The parallel-bond tensile strengths of sandstone and coal are 24.0 MPa and $40.0 \mathrm{MPa}$, individually. The parallel-bond cohesive strength of coal is higher than that of sandstone: $15.0 \mathrm{MPa}$ versus 8.4 MPa.

In PFC, numerical calibration requires back calculations using measured values of some commonly measured rock 

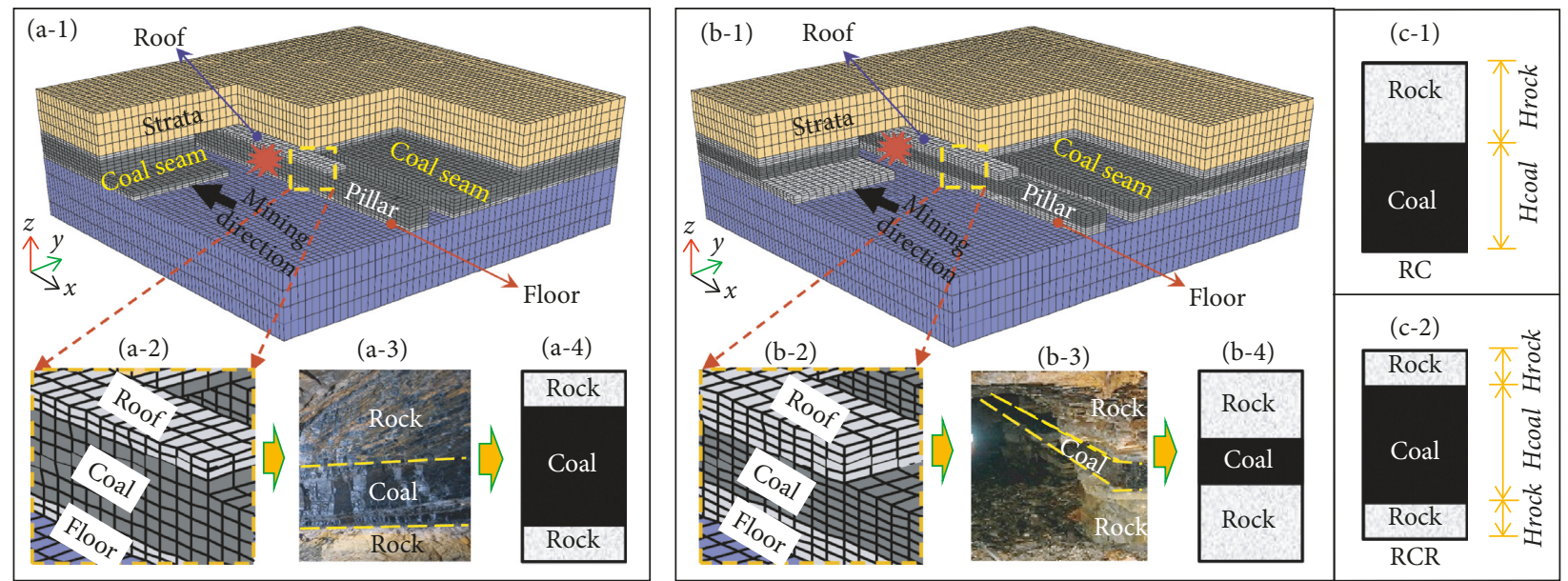

Figure 1: Coal pillars with two different geometries in longwall mining systems. The lower figures are in situ roof-coal-floor combinations and simplified RCR samples. (a-1) and (b-1) are the 3D schematics of longwall mining systems. (a-2) and (b-2) are the magnified figures of pillars. (a-3) and (b-3) are the two kinds of in situ roof-coal-floor structures with different height ratios. (a-4) and (b-4) are the schematics of RCR samples with different height ratios. (c-1) Rock-coal (RC) sample. (c-2) Rock-coal-rock (RCR) sample.

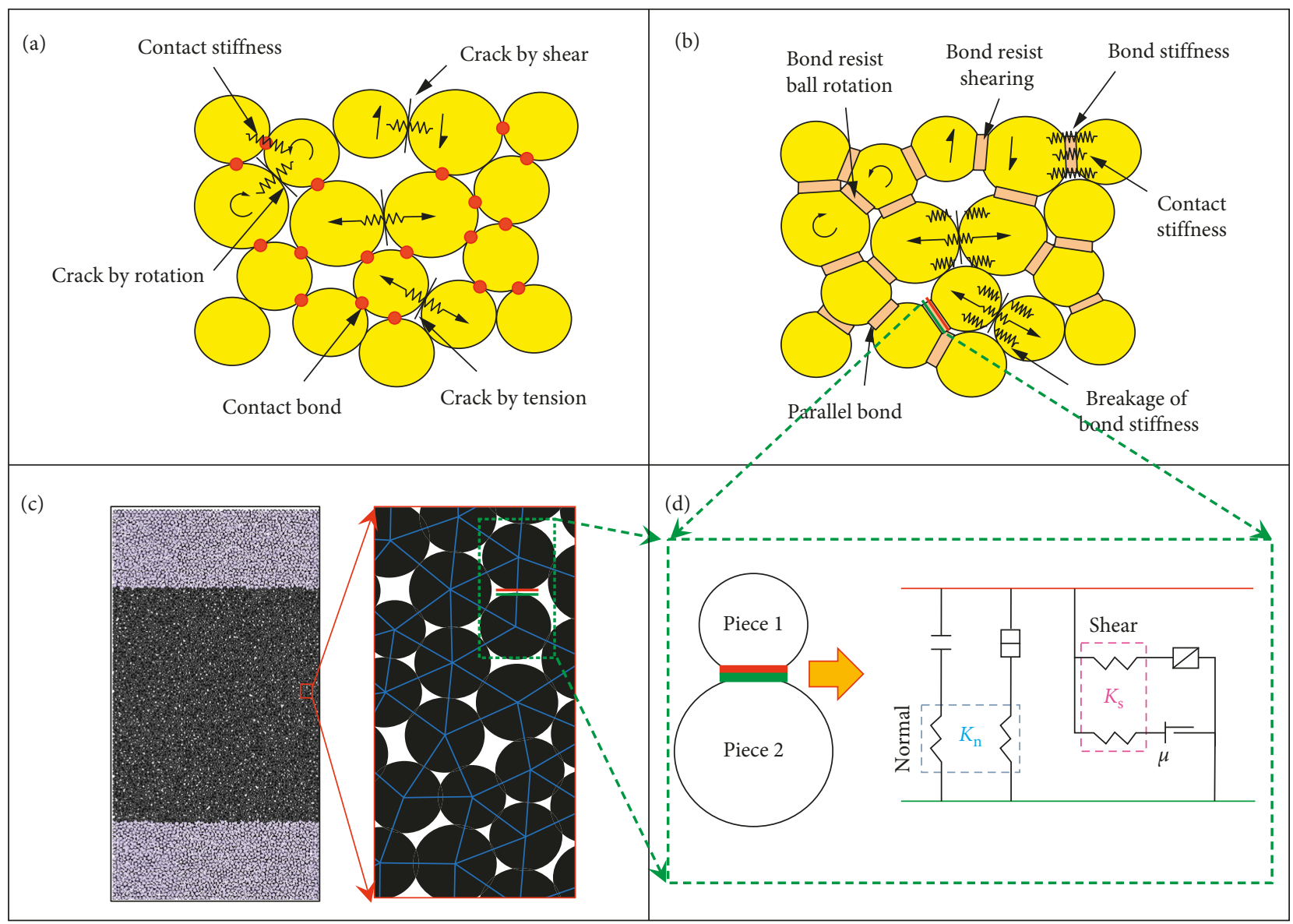

FIgURe 2: Illustration of bond models in PFC and numerical sample. (a) and (b) are contact-bond model (CBM) and parallel-bond model (PBM), respectively (modified from Cho et al. [30]). (c) A typical numerical RCR sample in this study. (d) Components of the linear parallelbond model (modified from Itasca [28])), where $K_{\mathrm{n}}, K_{\mathrm{s}}$, and $\mu$ represent normal stiffness, shear stiffness, and friction coefficient at a contact point, respectively. 

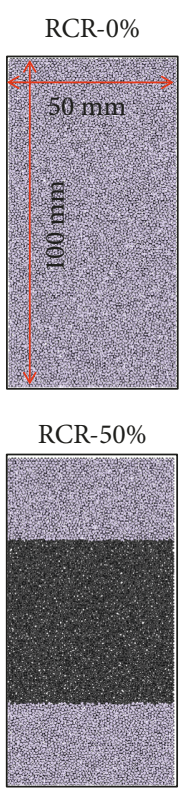

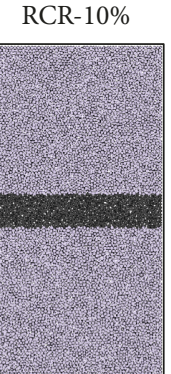

RCR-60\%

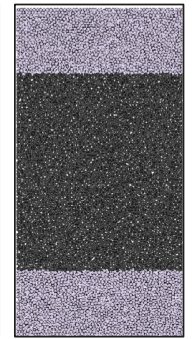

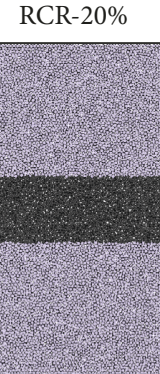

RCR- $80 \%$

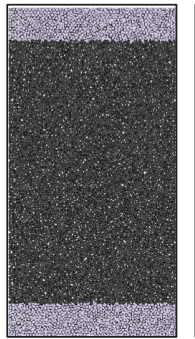

(a)

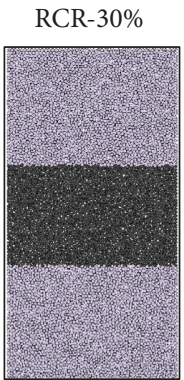

RCR-100\%
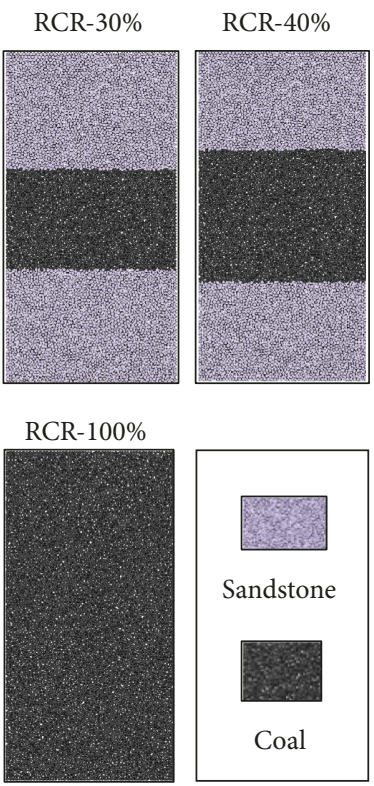

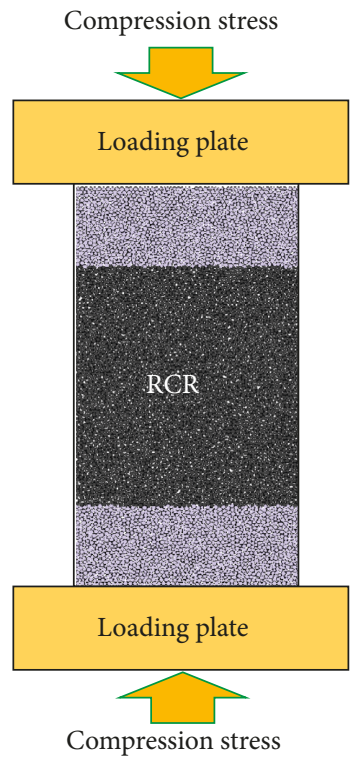

(b)

Figure 3: Numerical RCR samples with height ratios ranging from $0 \%$ to $100 \%$ (a), and the framework of uniaxial compression test (b).

properties, such as elastic modulus and UCS. Table 1 presents the calibrated results, which are comparisons between experimental and numerical data of sandstone and coal samples under uniaxial compression tests, and the coal and sandstone were taken from Yunhe coal mine (Jining, Shandong Province, China) [14].

\subsection{Microcracking Activity Measurement and Testing Procedures}

2.3.1. Microcracking Activity Measurement Method. In order to understand the failure mechanisms in rock, monitoring AE events caused by microcracking activities is always employed [35-37]. In PFC, bond breakages can be simultaneously monitored using the program's internal language (FISH). Furthermore, the initiation and propagation of microcrack can be represented as a progressive breakage of contact bonds [28, 35]. Therefore, the microcracking activities were historically recorded by monitoring the bond breakage events.

2.3.2. Uniaxial Compression Method. During the test, an external load was applied on the top of the RCR sample in the axial direction (Figure 3(b)). As recommended by the user manual of PFC [28], the loading rate for compression tests was set as $0.02 \mathrm{~m} / \mathrm{s}$. It should be noted that the numerical loading rate is related to time step, which is different from that employed in laboratory tests. In this word, the time step in each calculation cycle was $1.16 \times 10^{-7} \mathrm{~s}$. Thus, the loading rate of $0.02 \mathrm{~m} / \mathrm{s}$ can be translated to $2.32 \times 10^{-6} \mathrm{~mm} / \mathrm{step}$, which means that it requires more than 431,000 steps to move the loading plate $1.0 \mathrm{~mm}$. A brief
TABLE 1: Calibrated results [14].

\begin{tabular}{lcccc}
\hline \multirow{2}{*}{ Rock type } & \multicolumn{2}{c}{ Peak strength $(\mathrm{MPa})$} & \multicolumn{2}{c}{ Elastic modulus (GPa) } \\
& Experimental & Numerical & Experimental & Numerical \\
\hline Sandstone & 87.30 & 89.30 & 8.13 & 8.37 \\
Coal & 29.24 & 30.60 & 3.06 & 3.11 \\
\hline
\end{tabular}

review of the loading rate setting in PFC can be found in the research of Zhang and Wong [38].

The simulated samples were compacted and tested as follows. (1) Generating an RCR sample; (2) removing floating particles; (3) identifying the coal component; (4) applying linear parallel contact bond to particles and setting the mechanical properties of the RCR sample; (5) applying a constant velocity of $0.02 \mathrm{~m} / \mathrm{s}$ on the top wall in all numerical runs; and (6) ceasing the compression process until $40 \%$ of the UCS is reached. During the loading process, mechanical and physical parameters (e.g., axial compression stress, axial strain and bond breakage events) were recorded in real time.

\section{Results and Discussion}

Axial stress-strain curves for RCR samples under uniaxial compression tests are shown in Figure 4, in which the stressstrain curves of the pure sandstone sample (height ratio equals to $0 \%$ ) and pure coal sample (height ratio equals to $100 \%)$ are also plotted. The curves of the RCR samples are located between those of pure sandstone and pure coal samples. From the shapes of these curves, it is clear that the height ratio has a key effect on the mechanical properties and deformation behavior of RCR samples, which will be analyzed in detail. 


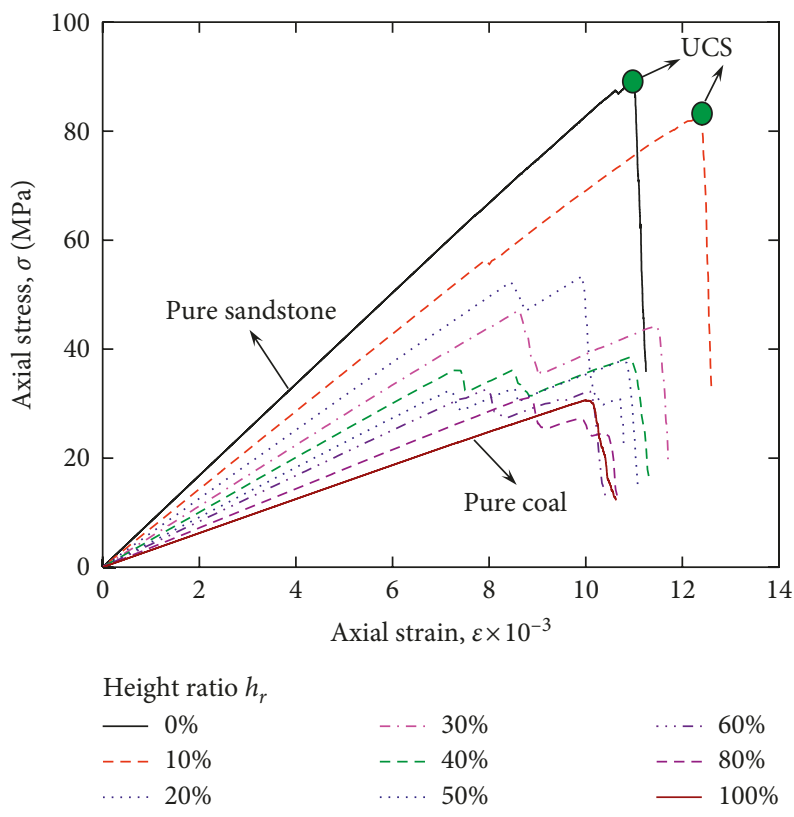

FIgURE 4: Stress-strain curves of the samples.

3.1. Effect of Height Ratio on the UCS of RCR Samples. In this section, the influence of the height ratio on the UCS of the RCR sample is investigated. In accordance with the stressstrain curves shown in Figure 4, the UCS values $\left(\sigma_{c}\right)$ for all samples are given in Table 2 and presented graphically in Figure 5. Generally, the UCS decreases with increasing height ratio. Specifically, the UCS values of RCR samples are all lower than that of pure sandstone $(89.36 \mathrm{MPa})$ and higher than that of the pure coal sample $(30.64 \mathrm{MPa})$, which is consistent with previous studies $[14,16]$. Figure 5 demonstrates the relation between height ratio $\left(h_{r}\right)$ and UCS $\left(\sigma_{c}\right)$ of samples (namely, $h_{r} \sim \sigma_{c}$ relationship), and the relationship can be illustrated by an inversed proportional function:

$$
\sigma_{c}=24.7+\frac{5.85}{h_{r}},
$$

where $\sigma_{c}$ and $h_{r}$ are UCS (MPa) and height ratio of the RCR sample, respectively.

The decreasing trend of the $h_{r} \sim \sigma_{c}$ curve is most pronounced for the RCR and pure coal samples, and the correlation coefficient of the regressive curve is 0.992 . According to the UCS values, the $h_{r} \sim \sigma_{c}$ curve can be divided into three stages. In stage I (i.e., height ratios between $10 \%$ and $40 \%$ ), the UCS decreases sharply from $82.89 \mathrm{MPa}$ to $38.57 \mathrm{MPa}$. In stage II (i.e., $40 \%$ to $60 \%$ ), the UCS experiences a slight decrease from $38.57 \mathrm{MPa}$ to $32.72 \mathrm{MPa}$, while a proximate stable trend can be identified afterward in stage III (from $32.72 \mathrm{MPa}$ to $31.14 \mathrm{MPa}$ ). Therefore, the critical height ratios of $40 \%$ and $60 \%$ may have key effects on both the mechanical and deformation behavior of RCR samples.

In quasistatic compression of the RCR sample, the load is equally applied on the tops of coal and rock components.
Once the external load reaches the UCS of the coal component, failure of coal would occur and the whole RCR sample may lose load-bearing capacity. Thus, the UCS of the RCR is determined by the strength of coal [12]. However, it is not always the same for composite samples with variable height ratios [14]. From Figure 5, it can be concluded that the UCS of the RCR sample is strongly influenced by the height ratio. Thus, a question may be posed: does the UCS of the RCR sample determined by the size effect of coal or rock component?

In this part, the size effects on the UCS of individual rock component and RCR sample were studied. Tuncay and Hasancebi [39] reviewed the size effect of length to diameter ratio on the UCS of the sample, indicating that the heightdiameter ratio is highly correlated with USC of the rock sample. Hoek and Brown [40] suggested that the UCS decreases with increasing sample diameter (Figure 6(a)), and they suggested the following equation to convert the UCS value of a different diameter sample to that of a $50 \mathrm{~mm}$ sample:

$$
\frac{\mathrm{UCS}}{\mathrm{UCS}_{50}}=\left(\frac{50}{\varphi}\right)^{0.18}
$$

where $\mathrm{UCS}_{50}$ is the UCS of the sample with a diameter of $50 \mathrm{~mm}$ (ASTM standard). $\varphi$ is the diameter of a test sample. Notice, the height of all samples employed in this method is $100 \mathrm{~mm}$ (Figure 6(a)).

According to the definition of the height-diameter ratio, the height ratio $\left(h_{r}\right)$ of an RCR sample can be converted into the height-diameter ratio. As shown in Figure 6, an individual coal or rock component can be represented by a pure sample with a height of $100 \mathrm{~mm}$. However, the diameter of the pure sample should be zoomed out or zoomed in according to the height-diameter ratio. 
TABLE 2: Uniaxial compressive strength, elastic modulus, and postpeak modulus of RCR samples.

\begin{tabular}{lcccccc}
\hline Sample & Height ratio $\left(h_{r}\right)$ & Size $(\mathrm{mm})$ & $\sigma_{c}(\mathrm{MPa})$ & $E(\mathrm{GPa})$ & $E_{r}(\mathrm{GPa})$ & Note \\
\hline RCR-0\% & $0 \%$ & $\varphi 50 \times 100$ & 89.36 & 8.37 & -225.19 & Pure sandstone \\
RCR-10\% & $10 \%$ & $\varphi 50 \times 100$ & 82.89 & 7.10 & -270.09 & RCR \\
RCR-20\% & $20 \%$ & $\varphi 50 \times 100$ & 53.30 & 6.23 & -235.00 & RCR \\
RCR-30\% & $30 \%$ & $\varphi 50 \times 100$ & 47.05 & 5.52 & -114.50 & RCR \\
RCR-40\% & $40 \%$ & $\varphi 50 \times 100$ & 38.57 & 4.95 & -65.03 & RCR \\
RCR-50\% & $50 \%$ & $\varphi 50 \times 100$ & 37.94 & 4.54 & -104.16 & -75.39 \\
RCR-60\% & $60 \%$ & $\varphi 50 \times 100$ & 32.72 & 4.16 & -78.76 & RCR \\
RCR-80\% & $80 \%$ & $\varphi 50 \times 100$ & 31.14 & 3.58 & -38.98 & RCR \\
RCR-100 & $100 \%$ & $\varphi 50 \times 100$ & 30.64 & 3.11 & & Pure coal \\
\hline
\end{tabular}

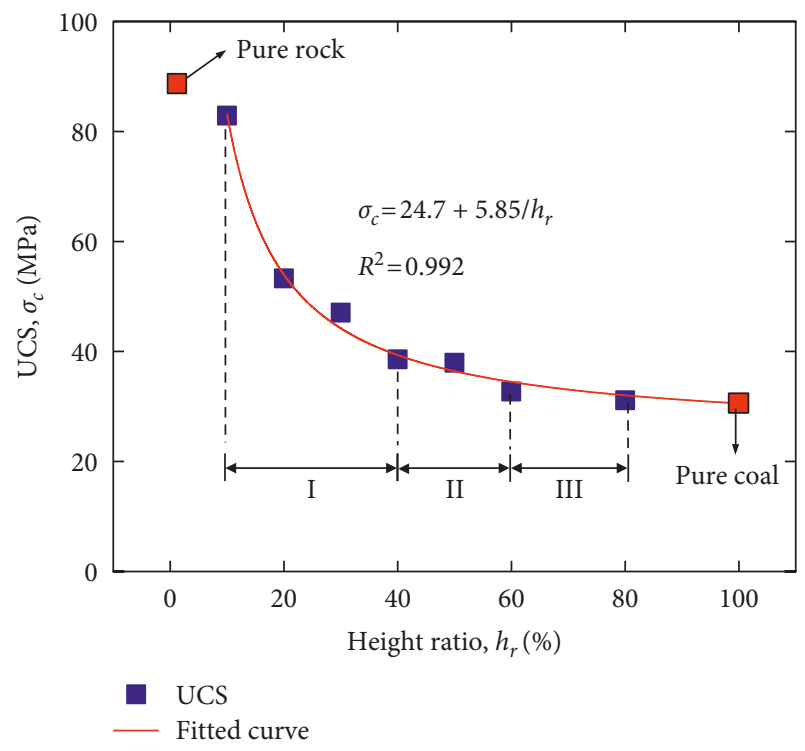

FIgURE 5: Relation between height ratio and UCS.

Based on Equation (2), the theoretical UCS/ $\mathrm{UCS}_{50}$ values of sandstone and coal components in an RCR sample can be calculated and plotted in Figure 7. In accordance with the UCS values of RCR samples shown in Table 2, the numerical UCS/UCS ${ }_{50}$ values of coal and rock components in RCR samples are also plotted. Interestingly, the theoretical curve is between the numerical curves of rock and coal samples. Furthermore, the numerical UCS/UCS ${ }_{50}$ curve of the sandstone component has a similar trend with the theoretical curve, while the numerical curve of the coal component experiences a reversed shape. Therefore, the $h_{r} \sim \sigma_{c}$ relationship cannot be simply illustrated as a result of size effect but may also be caused by the effect of coal-rock interface [20]. The strength of weak coal is enhanced near the interface, while the strength of sandstone is weakened, thus the global strength may be modified.

\subsection{Effects of Height Ratio on the Elastic and Postpeak Modulus of RCR Samples}

3.2.1. Relation between Height Ratio and Elastic Modulus. The elastic modulus $(E)$ is a mechanical property of an object which represents resistance to being deformed elastically when loading. In a stress-strain curve, the elastic modulus is defined as the slope of the elastic deformation region (Figure 8). At the stage of elastic deformation, the compression stress increases linearly with axial strain, and the elastic deformation dominates a stress-strain curve in the prepeak stage. According to the stress-strain curves shown in Figure 4, the elastic modulus values of RCR samples which are listed in Table 2 and presented in Figure 9 can be regressively derived. The relation between height ratio and elastic modulus (namely, $h_{r} \sim E$ relationship) is also presented.

As shown in Figure 9, the height ratio has a key effect on the value of the elastic modulus. The elastic modulus values of RCR samples are between the values of pure sandstone $(7.10 \mathrm{GPa})$ and pure coal $(3.11 \mathrm{GPa})$ samples. On the whole, the elastic modulus of the sample nonlinearly decreases with increasing height ratio. According to the regressive curve, the $h_{r} \sim E$ relationship of the RCR sample is expressed as

$$
E=2.58-5.58 \times 0.1196^{h_{r}},
$$

where $E$ and $h_{r}$ are the elastic modulus (GPa) and the height ratio of the RCR sample, respectively.

As mentioned in Section 3.1, the effect of rock-coal interface should be taken into consideration when analyzing the UCS of RCR samples. In an RCR, the frictional force exists on the rock-coal interface to restrict the deformation of rock and coal, which is different from the no-frictional interface in the idealized sample (Figure 10(a)). Thus, a mechanical model was established (Figure 10) and discussed in the following parts.

Let $E_{\text {rock }}, E_{\text {coal }}$, and $K_{\text {rock }}, K_{\text {rock }}$ denote, respectively, the elastic modulus and stiffness where the subscripts "coal" and "rock" identify the coal and rock components, and suppose $E_{\text {rock }}>E_{\text {coal }}$ and $K_{\text {rock }}<K_{\text {coal }}$. It is known that the stiffness of a rock is a measure of the resistance offered by an elastic body to deformation. For an elastic rock, the stiffness is defined as

$$
K=\frac{F}{\delta}
$$

where $F$ and $\delta$ are external load on the top of an elastic body and elastic deformation, respectively.

For the series-connected sample (Figure 10(a)), the rockcoal interaction at a connecting layer can be neglected due to the eliminated friction caused by rollers. The stiffness of such series-connected sample, $K_{w}$, can be expressed as 


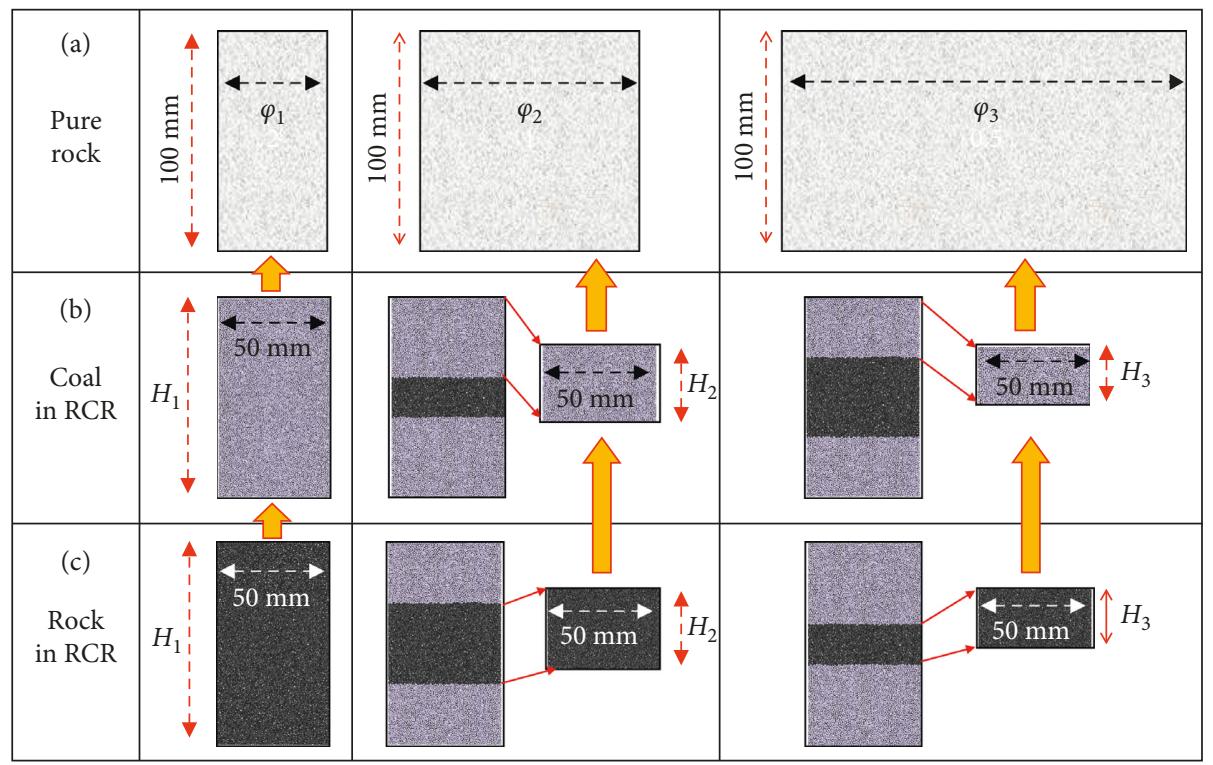

Figure 6: Size effect of samples. (a) Samples with a constant height $(100 \mathrm{~mm})$ employed in Equation (2). (b) Rock components with a constant diameter of $50 \mathrm{~mm}$ and different heights $\left(H_{1} \sim H_{3}\right)$ in RCR samples. (c) Coal bodies with a constant diameter of $50 \mathrm{~mm}$ and different heights $\left(H_{1} \sim H_{3}\right)$ in RCR samples.

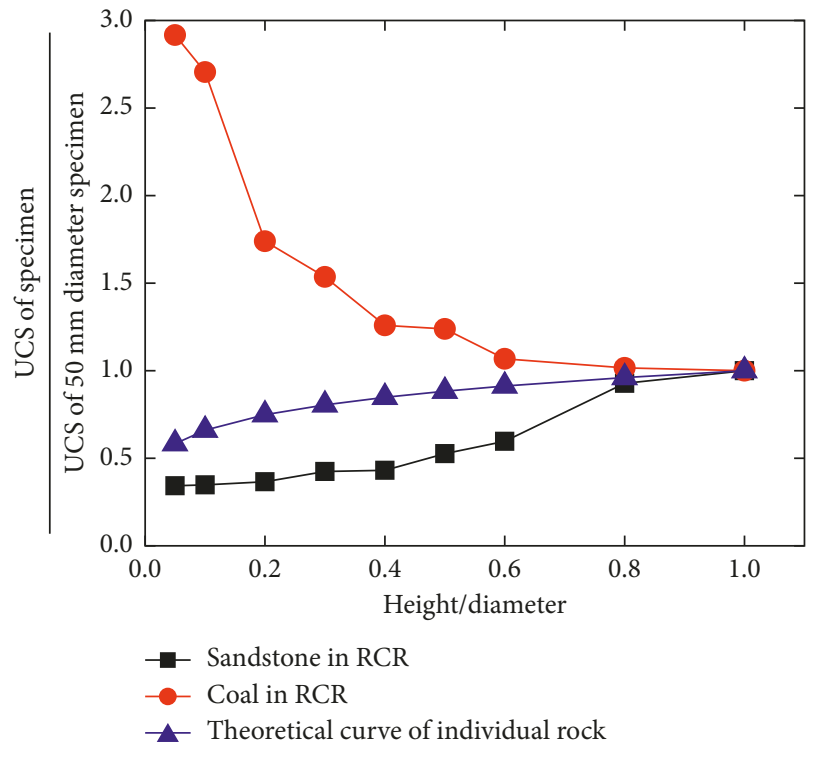

FIGURE 7: Size effect on the UCS of the samples.

$$
K_{w}=\frac{1}{\sum_{i=1}^{n}\left(1 / K_{i}\right)},
$$

where $K_{w}$ is the stiffness of the composite sample, $\mathrm{N} / \mathrm{m} ; K_{i}$ is the stiffness of an individual component; and $n$ refers to the number of components.

The elastic modulus of a material is not the same as the stiffness of a component made from that material [43]. Specifically, stiffness is an extensive property of the elastic body that is dependent on the material properties, shape, and boundary conditions. For a rock in compression, the axial stiffness is

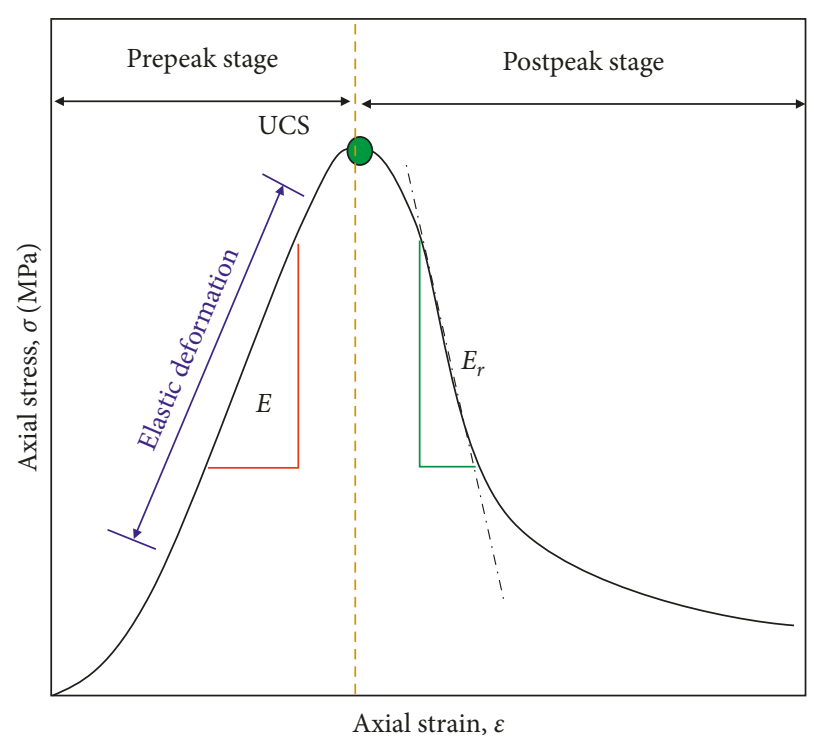

FIgUre 8: The USC, elastic modulus, and postpeak modulus in a typical stress-strain curve [41, 42].

$$
K=\frac{E A}{H}
$$

where $E$ is the elastic modulus of samples. $A$ and $H$ are the cross-sectional area and height of a rock, respectively.

By arranging Equations (5) and (6), the elastic modulus of a composite sample without interface friction can be obtained as follows:

$$
E_{w}=\frac{H}{A \sum_{i=1}^{n}\left(H_{i} / E_{i} A_{i}\right)},
$$




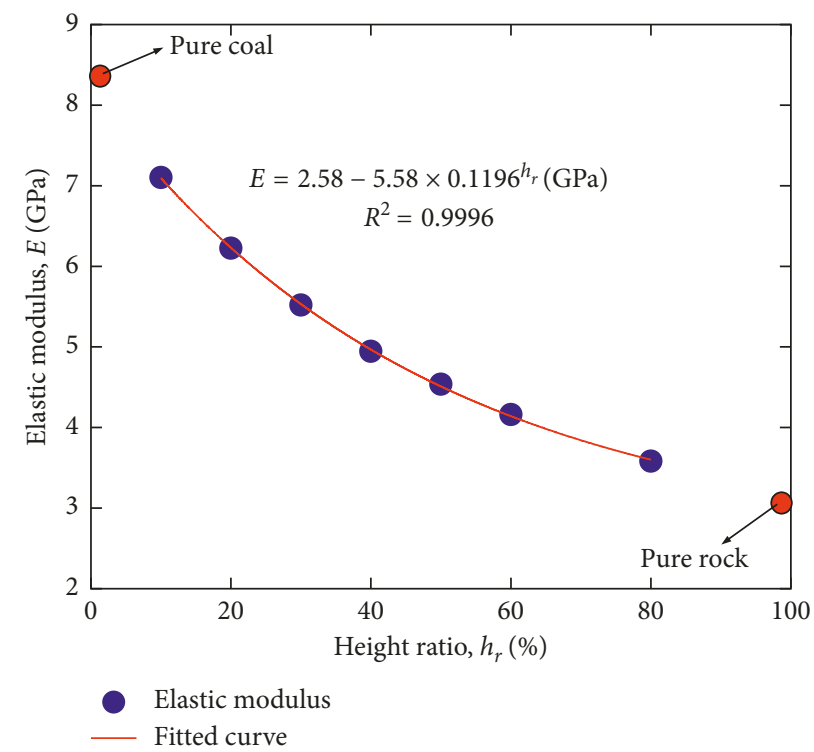

Figure 9: Relationship between height ratio and elastic modulus.

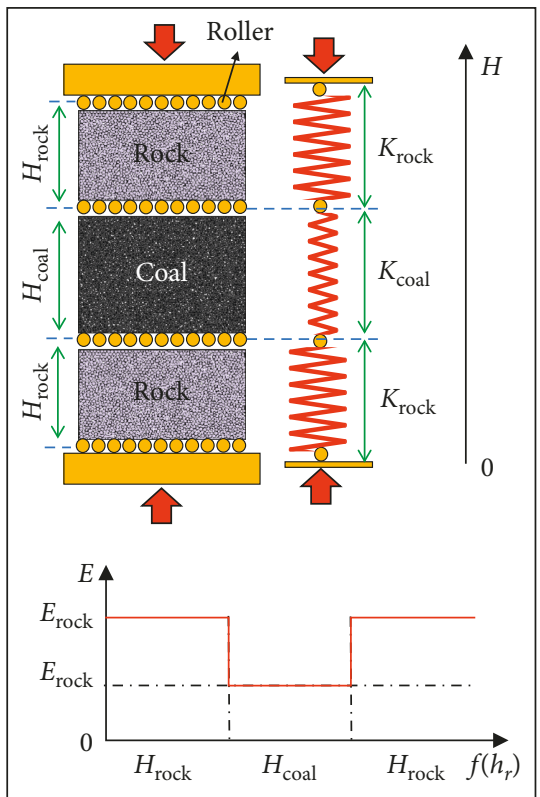

(a)

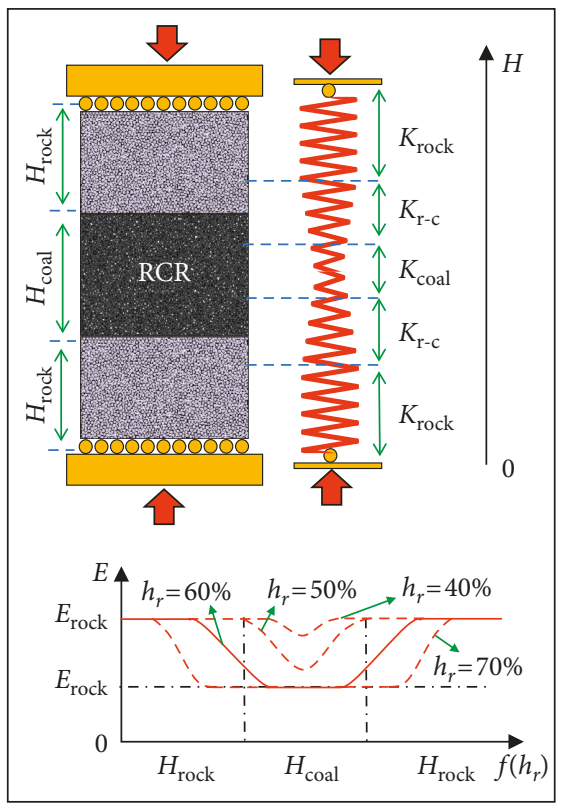

(b)

FIGURE 10: Mechanical models of the RCR samples. (a) Series-connected sample without rock-coal surface interaction, in which rollers are installed to reduce the friction. The lower represents the elastic modulus versus height of the series-connected sample. (b) RCR sample with rock-coal surface friction. The lower shows the elastic modulus versus height of the RCR sample. In the rock-coal interface area, the elastic modulus gradually changes from $E_{\text {rock }}$ to $E_{\text {coal }}$.

where $E_{w}$ is the elastic modulus of the composite sample without interface friction. $A_{i}, H_{i}$, and $E_{i}$ are the cross-sectional area, elastic modulus, and the height of individual component, respectively.

In the RCR (Figure 10(b)), the mechanical properties of a composite sample not only are influenced by the size effect but may also by the effect of the rock-coal interface. Considering the elastic modulus of the area of rock-coal interface
$\left(K_{r-c}\right)$ is nonconstant, but it varies with the height of this area, which is different from that of the series-connected sample shown in Figure 10(a). By taking Saint-Venant's principle (i.e., boundary conditions) into consideration [44], the elastic modulus of an RCR can be expressed as

$$
E_{w}=\frac{H}{\sum_{i=1}^{n}\left(f_{\left(h_{r}\right)}^{i} / f_{\left(E_{i}\right)}\right)} .
$$


With

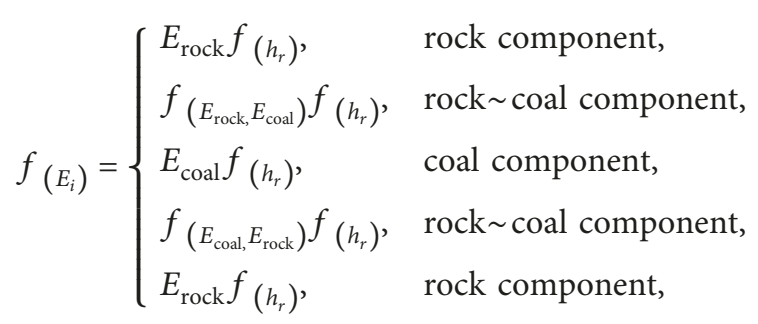

where $f_{\left(E_{i}\right)}$ is the function of the elastic modulus of a component, $f_{\left(h_{r}\right)}$ is a shape function that determines the heights of components, and $f_{\left(E_{\text {coal }}, E_{\text {rock }}\right)}$ is the elastic modulus in the area of rock-coal interface.

The elastic modulus along the height of the RCR sample can be primarily depicted in the below parts of Figure 10. According to Equation (5), the elastic modulus of the seriescomposite sample (Figure 10(a)) is a constant value and is unrelated to the height ratio. However, as can be seen easily in Figure 10(b), the elastic modulus along the height of the RCR sample gradually changes from $E_{\text {rock }}$ to $E_{\text {coal }}$, which is different from that of the series-connected sample (Figure 10(a)). Further, according to Equation (7), the height ratio has a key effect on the elastic modulus along the height, because the height ratio determines the values of the elastic modulus in rock-coal areas. Therefore, the coupled effects of the height ratio and elastic modulus of each component may result in the nonlinear phenomena in $h_{r} \sim \sigma_{c}$ and $h_{r} \sim E$ curves.

\subsubsection{Relation between Height Ratio and Postpeak Modulus.} The postpeak stage of a typical strain-strain curve shows that the strength decreases with increasing strain (Figure 8). The postpeak modulus $\left(E_{r}\right)$ [42], determined based on the progress of a postpeak failure stage, is a mechanical parameter of great importance in solving mining geomechanics problems. The value of postpeak modulus is determined by the tangent of angle of the inclination of a line being a linear approximation of the stress-strain curve. More detailed descriptions on the postpeak modulus can be found in the research of Bukowska [41].

The approximate linear portions of postpeak stages are plotted in Figure 11, in which linear fitted curves are also presented. The correlation coefficients of these linear fitted curves are between 0.953 and 0.993 . The values of the postpeak modulus are listed in detail in Table 2. It can be seen that the postpeak modulus of pure sandstone and pure coal samples are $-225.19 \mathrm{GPa}$ and $-38.98 \mathrm{GPa}$, respectively. In Figure 12, $h_{r} \sim E_{r}$ relationship is graphically presented. It is clear that the postpeak modulus grows up with increasing height ratio as an inversely proportional function which can be illustrated as

$$
E_{r}=-43.8-24.7 / h_{r}
$$

where $E_{r}$ and $h_{r}$ are postpeak modulus (GPa) and height ratio of RCR sample, respectively.
The fitted $h_{r} \sim E_{r}$ curve is primarily divided into two stages by the critical height ratio of $40 \%$. In stage $\mathrm{A}$, the postpeak modulus increases sharply with height ratio $(10 \%-40 \%)$, which means the postpeak curve tends to fall more rapidly with a steeper slope in the postpeak stage. However, in stage $B$, the postpeak modulus keeps stable with increasing height ratio (above 40\%).

\subsection{Effect of Height Ratio on the Microcracking Activity of} Samples. The microcracking activity can be presented and counted by monitoring bond breakage events in PFC [28]. Figure 13 shows the stress-strain curves and microcracking evolutions of pure sandstone and pure coal samples during the whole loading history, while Figure 14 shows those of RCR samples. In accordance with the microcracking activity and stress-strain results, a detailed investigation for the microcrack characteristics of pure and composite samples was carried out.

In Figure 13, the microcracking activity of pure samples is divided into two periods, namely, the quiet period and the active period. During the quiet period, there is no bond breakage, and the stress linearly grows up with increasing strain. During the active period, stress-strain curves of pure sandstone and coal samples undergo two different stages, i.e., the stage of elastic deformation and the stage of crack growth and propagation. Moreover, microcracking activities of the pure coal sample are much more intense than those of the pure rock sample. This is because the sandstone with a higher brittleness experienced a sharp stress drop after failure, while the coal sample failed in a progressive manner.

The microcrack characteristics of RCR samples are different from those of pure samples. As shown in Figure 14, the reactive period occurs after the quiet and active periods. The microcracking behavior of RCR samples during the quiet period is not dependent on the height ratio. In the active period, the stress increases linearly at the stage of elastic deformation. However, when it increases to small peak stress, the stress-strain curve occurs to depart from the linear curve and shows distinctly stress drop behavior. After the active period, another active period (i.e., reactive period) occurs, because the propagation of microcrack causes the redistribution of the contact force. As shown in the elliptical zones in Figure 14, the RCR samples progressively fails. It can be seen that before the failure of the whole sample, the component of coal fails with several stress drops.

\subsection{Discussion on the Failure Mode of RCR Samples}

\subsubsection{Validation of the Simulation Results}

(1) Comparison between the Simulation Results and Laboratory Test Results. In this section, we conducted a comparison between the simulation results and the laboratory test results. These final failure modes of RCR samples (RCR-20\% and RCR-40\%) are shown in Figure 15, wherein the left are simulation results and the right are laboratory test results. 

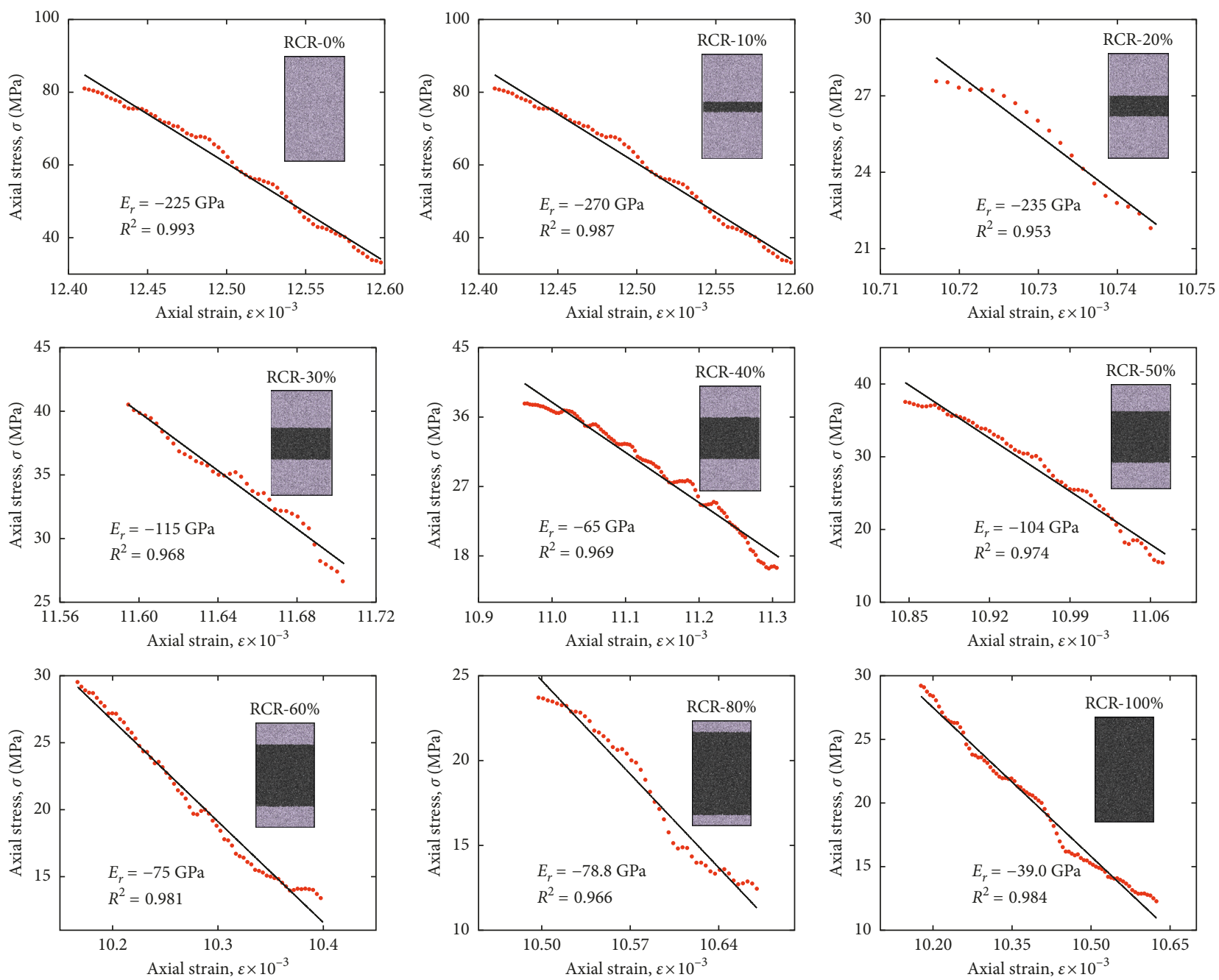

Figure 11: Postpeak stages and linear fitted curves.

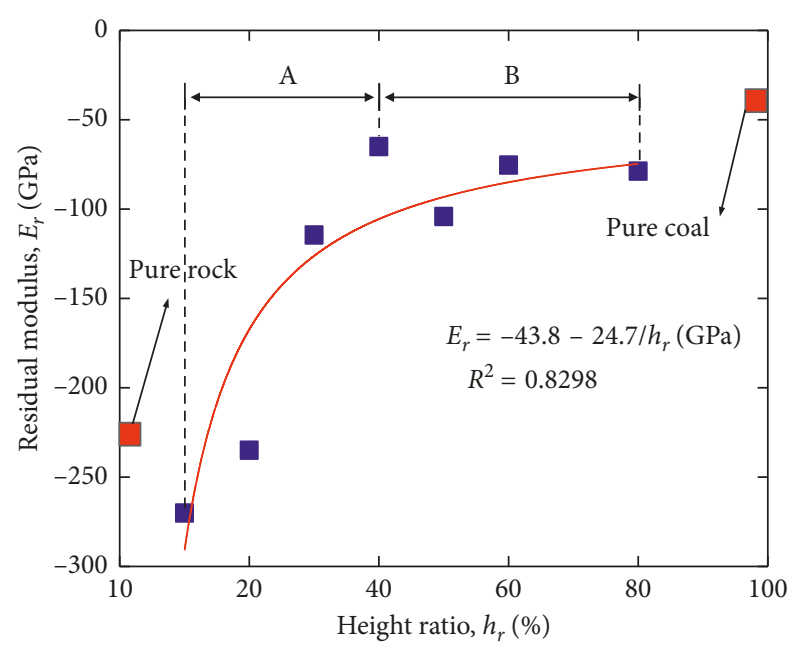

Figure 12: Relation between height ratio and the postpeak modulus.

The failure modes of laboratory test results are consistent with those of simulation results. As can be seen in Figure 15(a), with an increase of uniaxial compression stress, the deformation of rocks is not apparent and lateral deformation of the coal is marked and much greater than that of rocks; the coal ruptures vertically first. With further increase of compressive stress, the coal section splits and smashes into a columnar form; at the time of coal failure, the rock generates splitting failure rapidly. As can be seen from both the simulation and laboratory test results (Figure 15(b)), the coal bodies are broken more thoroughly than the rock bodies. The lower part of the coal body is tapered, suggesting that the X-type shearing fracture surface must have been formed inside the coal before failure. Shear fracture mainly occurs before splitting, and the final destruction of the coal is dominantly splitting [16].

(2) Comparison between the Simulation Results and the in Situ Test Results. Figure 16 presents the comparison between the simulation results and the in situ test results, wherein Figure 16(a) is the simulation failure mode of the RCR sample, and Figures 16(b) and 16(c) are the in situ failure modes. The in situ test pillar (Figure 16(b)) is about $2 \mathrm{~m}$ in width $[45,46]$.

In the coal component of the RCR sample, the conjugated shear bands can be easily identified (Figure 16(a)). Similarly, such conjugated shear bands can be identified in the in situ 


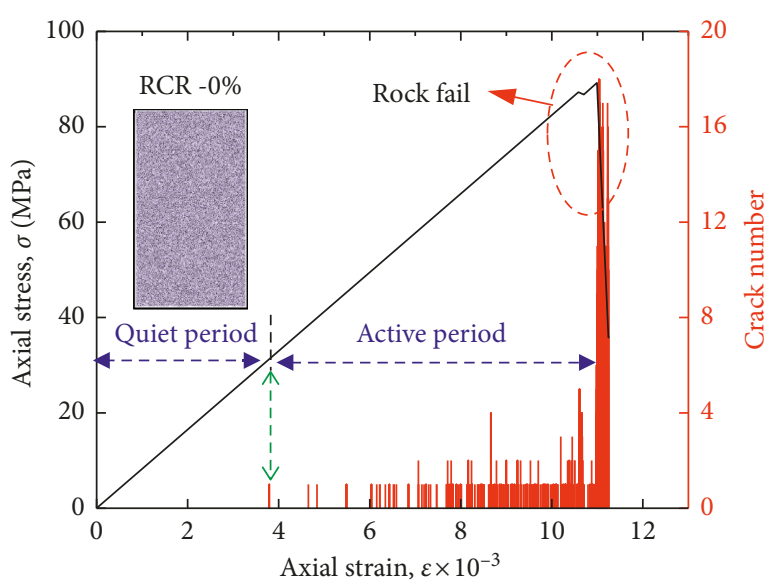

(a)

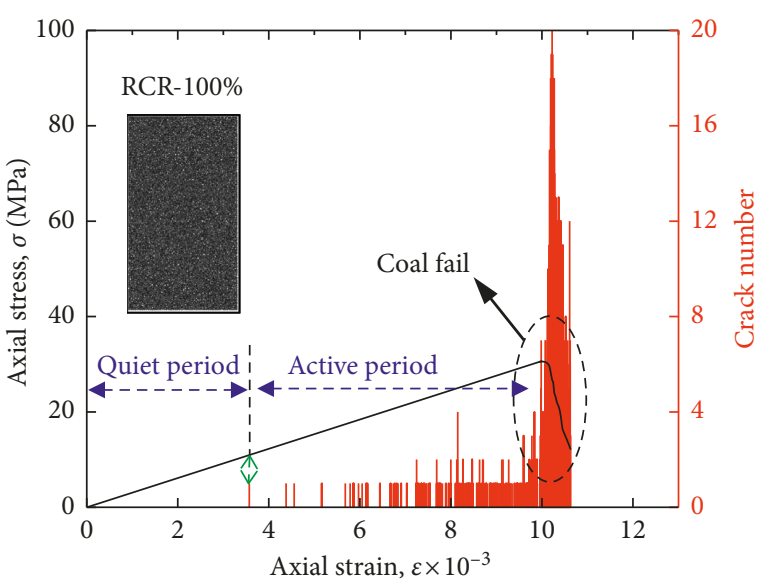

(b)

FIgURE 13: Microcracking evolution of pure sandstone (a) and pure coal (b) samples under uniaxial compression tests.

rock/coal pillars (Figure 16(b) and 16(c)). This failure mode was also called double-pyramid type of failure [46]. Generally, the influence on the pillar strength of the lateral confinement generated at the pillar ends decreases with distance from the end interfaces. As shown in Figure 16, this is evidenced by the hourglass shape of the stressed pillars. It is one reason why the strength of a pillar with a given width decreases with increasing pillar height. This is consistent with the effect of the height ratio on the failure mode of the RCR sample.

3.4.2. Effect of Height Ratio on the Failure Mode of RCR Sample. Figure 17 illustrates the influence of the height ratio on the ultimate failure modes of the RCR samples under uniaxial compression tests. The crack distributions are depicted as short colored lines, and the red line occurred later than the yellow and green lines.

In pure sandstone and pure coal samples, the conjugated shear bands can be easily identified. However, in the RCR samples, fractures initiated in coal components and then propagated to the whole RCR samples, resulting in multistress drops in the stress-strain curves (Figure 14). In accordance with the time-dependent microcracking activities shown in Figure 17, it can be concluded that the failure of coal component causes the first stress drop in the stressstrain curve, and the last stress drop results from the collapse of rock component or the whole sample.

3.5. Progressive Application of the Results. The failure of rock samples in laboratory testing is similar to the dynamic disasters in the field [47]. The pure coal sample experiences splitting and comminuting failure. However, the failure of the RCR sample is progressive. The cracking bands develop preferentially in the component of coal, and then the development of cracks gradually extends to the rock portion. This is because the constraint force exerted on the interface between the coal and the rock in the direction perpendicular to the axis is small, and the tensile stress caused by the radial expansion of the sample exceeds the tensile strength of coal first, thus resulting in a columnar splitting failure of the coal section [15].

The determiner, controlling the failure of the whole RCR sample, changes from rock to coal component with increasing height ratio. According to Figures 14 and 17, the critical height ratio can be identified as $60 \%$. Prior to the critical height ratio, the UCS of the RCR sample is determined by the failure of rock, while the UCS of the RCR sample is controlled by the failure of coal component afterward. We can wonder that the in situ roof-coal-floor structure experiences such progressive failure. Thus, the coal failure in the roof-coal-floor structure with a height ratio lower than $60 \%$ would not result in systematical failure, and the systematical failure often takes place after one or two dense $\mathrm{AE}$ events. However, if the height ratio of a roof-pillarfloor structure is higher than $60 \%$, the failure of coal would lead to systematical failure of the whole structure. These results may contribute to predicting the hazards of coal bursts and estimating the failure of rock-coal-floor structures in underground coal mining systems.

\section{Conclusions}

In this paper, we studied the mechanical properties and deformation behavior of RCR samples with variable height ratios ranging from 0 to $100 \%$. The effects of the height ratio on the UCS, elastic modulus, postpeak modulus, microcracking activity, and failure mode of RCR samples were systematically investigated. The following can be concluded:

(1) The UCS of the RCR sample is strongly affected by the height ratio, and the increase of the height ratio decreases the UCS as an inverse proportional function. In addition, the UCS versus height ratio curve is divided into three stages, namely, dramatical decrease stage (height ratio: 0 to $40 \%$ ), slight decrease stage (height ratio: $40 \%$ to $60 \%$ ), and stable stage (height ratio: $60 \%$ to $100 \%$ ).

(2) The elastic modulus tends to decrease exponentially with increasing height ratio, while the 

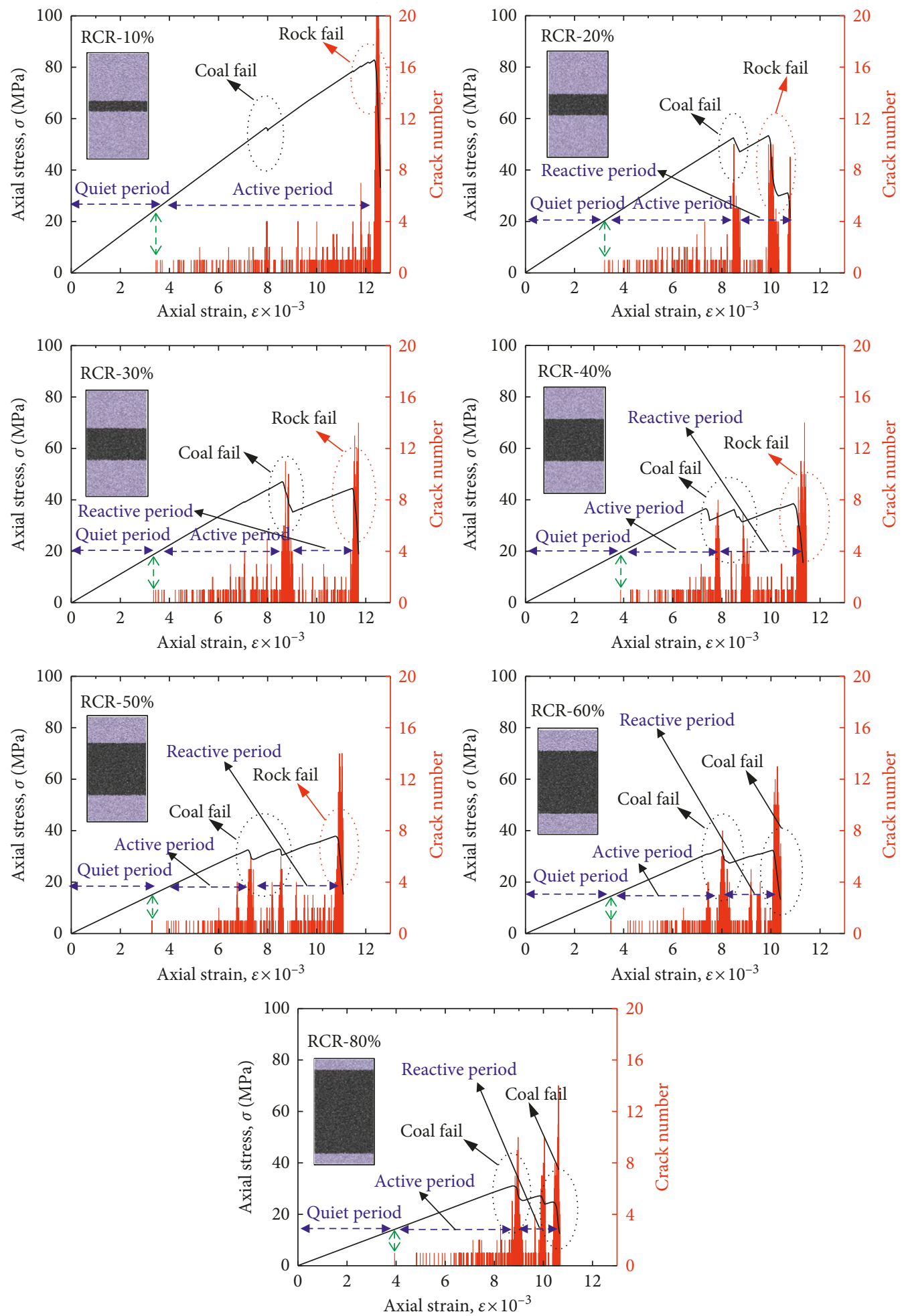

FIGURE 14: Relation between stress and microcracking evolution of RCR samples. 

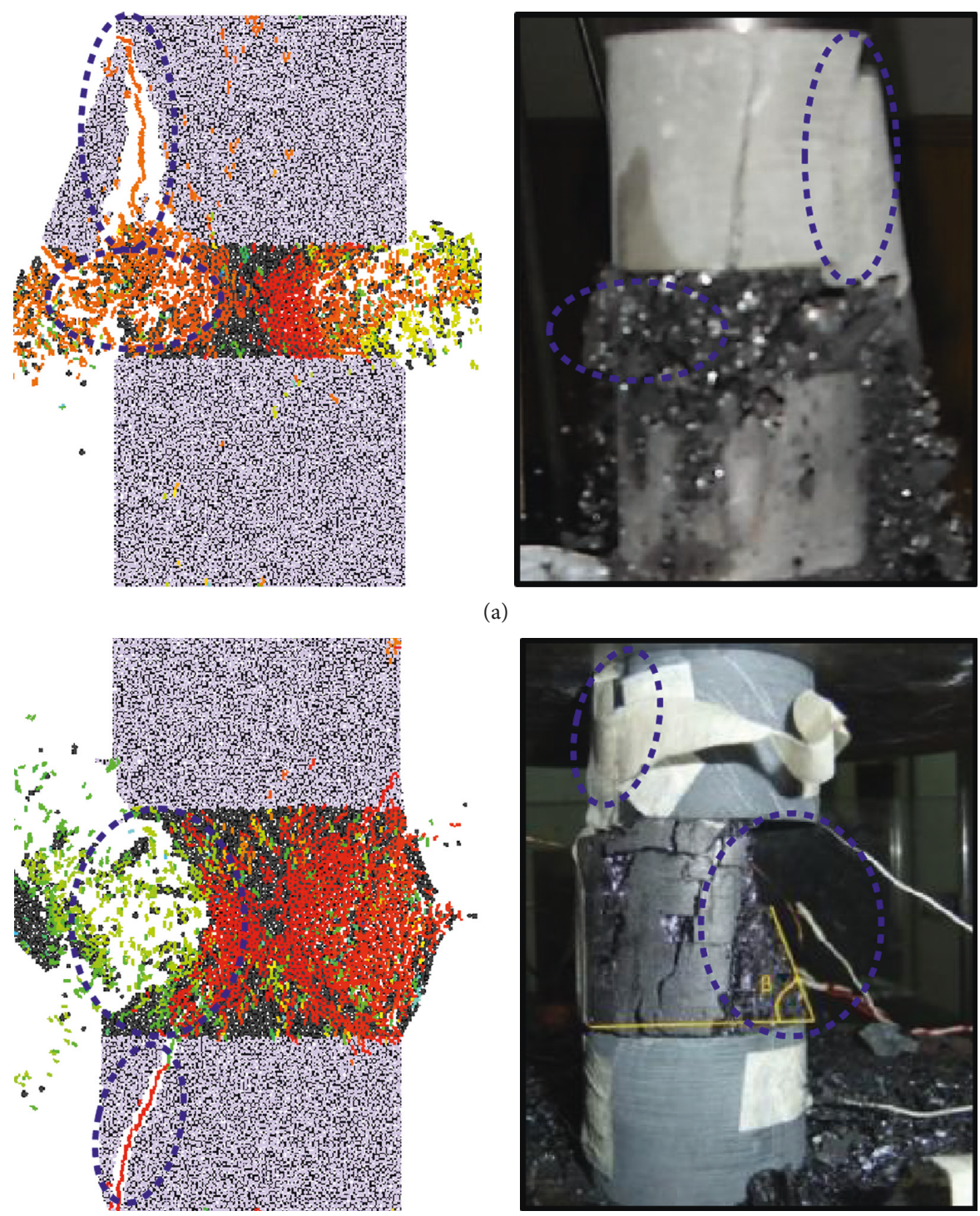

(a)

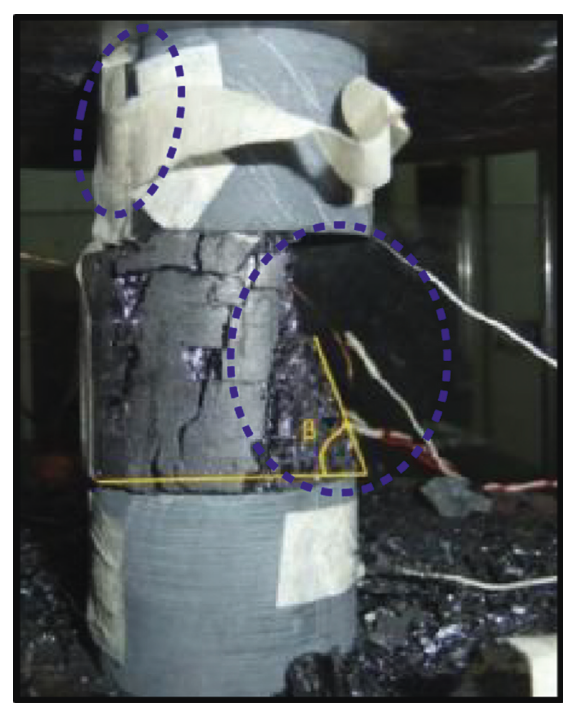

(b)

FIGURE 15: Comparison between the simulation results (left) and the laboratory test results (right). (a) Failure mode of the RCR sample with a height ratio of $\sim 20 \%$. The laboratory test result is derived from Huang and Liu [15]. (b) Failure mode of the RCR sample with a height ratio of $40 \%$. The laboratory test result is derived from Liu et al. [16].

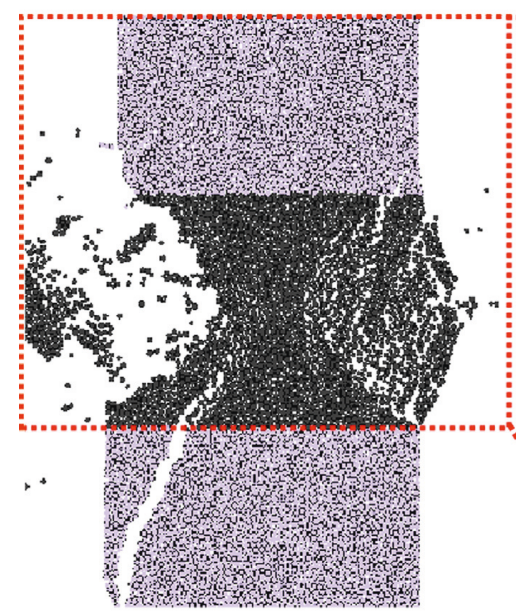

(a)

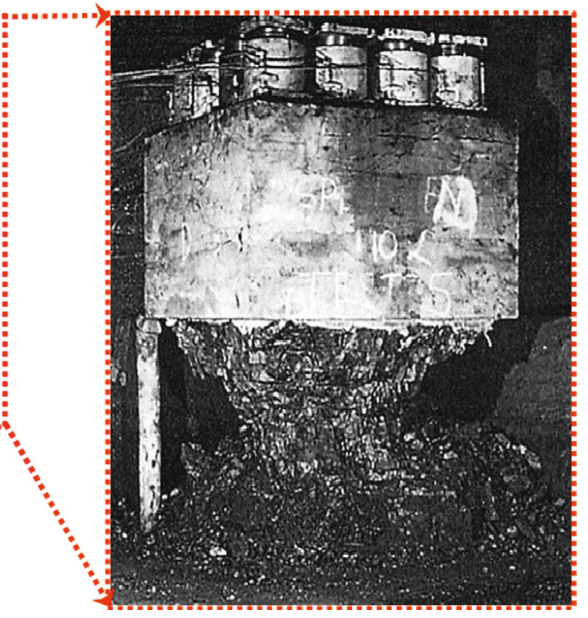

(b)

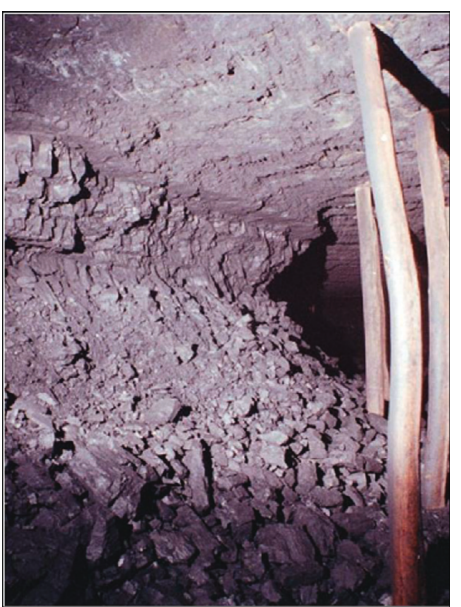

(c)

FIGURE 16: Comparison between the simulation results (left) and the in situ test results (right). (a) Failure mode of an RCR sample; (b) and (c) are the failure modes of the in situ pillars $[45,46]$. 


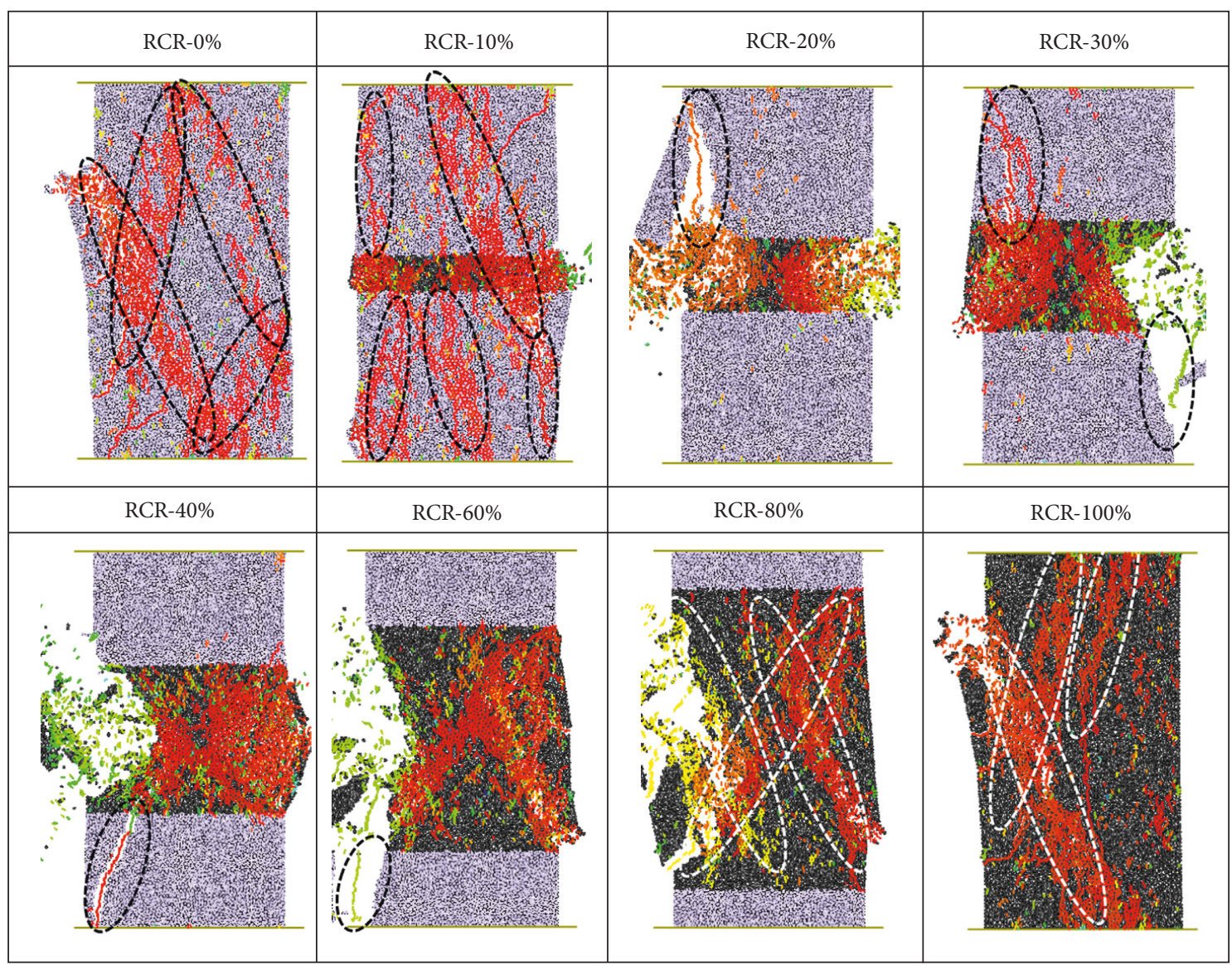

FIgURE 17: Failure modes of the RCR samples.

postpeak modulus value prefers to rise with the increasing height ratio in an inverse proportional manner.

(3) The microcracking activity of RCR samples is different from that of pure samples. The reactive period always occurs in RCR samples after the quiet and active periods. The active period in an RCR sample comes up with the failure of coal component, while the reactive period always implies the failure of the whole RCR sample.

(4) The RCR sample fails in a progressive manner. The cracking bands develop preferentially in the component of coal, and then the development of cracks gradually extends to rocks. However, the determiner of the UCS of the RCR sample varies in the height ratio. Prior to the critical height ratio of $60 \%$, the UCS is determined by the failure of rock, while the UCS is controlled by the failure of coal component afterward.

\section{Data Availability}

The data used to support the findings of this study are available from the corresponding author upon request.

\section{Conflicts of Interest}

The authors declare no conflicts of interest.

\section{Acknowledgments}

This work was supported by the National Basic Research Program of China (2014CB046300) and supported by the Priority Academic Program Development of Jiangsu Higher Education Institutions (PAPD).

\section{References}

[1] N. G. W. Cook, "Seismicity associated with mining," Engineering Geology, vol. 10, no. 2-4, pp. 99-122, 1976.

[2] L. Driad-Lebeau, F. Lahaie, M. A. Heib, J. P. Josien, P. Bigarré, and J. F. Noirel, "Seismic and geotechnical investigations following a rockburst in a complex french mining district," International Journal of Coal Geology, vol. 64, no. 1-2, pp. 66-78, 2005.

[3] L. Dou, C.P. Lu, Z. Mu, and M. Gao, "Prevention and forecasting of rock burst hazards in coal mines," International Journal of Mining Science and Technology, vol. 19, no. 5, pp. 585-591, 2009.

[4] Y. Jiang, H. Wang, S. Xue, Y. Zhao, J. Zhu, and X. Pang, "Assessment and mitigation of coal bump risk during 
extraction of an island longwall panel," International Journal of Coal Geology, vol. 95, pp. 20-33, 2012.

[5] Z. Li, L. Dou, W. Cai et al., "Failure-pillar induced rock burst mechanism of thick coal seam in deep mining," Chinese Journal of Rock Mechanics and Engineering, vol. 32, pp. 333-342, 2013.

[6] Y. Pan, Z. Li, and M. Zhang, "Distribution, type, mechanism and prevention of rockburst in China," Chinese Journal of Rock Mechanics and Engineering, vol. 22, pp. 1844-1851, 2003.

[7] C. Wang, F. Jiang, P. Wang et al., "Microseismic events distribution characteristics and mechanical mechanisms of rock bursting induced by a coal pillar," Journal of China Coal Society, vol. 34, pp. 1169-1173, 2009.

[8] C. P. Lu, L. M. Dou, B. Liu, Y. S. Xie, and H. S. Liu, "Microseismic low-frequency precursor effect of bursting failure of coal and rock," Journal of Applied Geophysics, vol. 79, pp. 55-63, 2012.

[9] E. Hoek and E. T. Brown, "Practical estimates of rock mass strength," International Journal of Rock Mechanics \& Mining Sciences, vol. 34, no. 8, pp. 1165-1186, 1997.

[10] T. P. Medhurst and E. T. Brown, "A study of the mechanical behaviour of coal for pillar design," International Journal of Rock Mechanics \& Mining Sciences, vol. 35, no. 8, pp. 10871105, 1998.

[11] H. Zhang, Z. Wan, D. Ma, Y. Zhang, J. Cheng, and Q. Zhang, "Experimental investigation on the strength and failure behavior of coal and synthetic materials under plane-strain biaxial compression,” Energies, vol. 10, p. 500, 2017.

[12] Z. Zhao, X. Lv, W. Wang, and Y. Tan, "Damage evolution of bi-body model composed of weakly cemented soft rock and coal considering different interface effect," Springerplus, vol. 5, p. 292, 2016.

[13] J. Zuo, H. Xie, W. U. Aimin, and J. Liu, "Investigation on failure mechanisms and mechanical behaviors of deep coalrock single body and combined body," Chinese Journal of Rock Mechanics \& Engineering, vol. 30, pp. 84-92, 2011.

[14] S. Chen, D. Yin, B. Zhang, H. Ma, and X. Liu, "Study on mechanical characteristics and progressive failure mechanism of roof-coal-pillar structure body Chinese," Journal of Rock Mechanics and Engineering, vol. 36, pp. 1-11, 2017.

[15] B. Huang and J. Liu, "The effect of loading rate on the behavior of samples composed of coal and rock," International Journal of Rock Mechanics \& Mining Sciences, vol. 61, pp. 23-30, 2013.

[16] J. Liu, E. Wang, D. Song, S. Wang, and Y. Niu, "Effect of rock strength on failure mode and mechanical behavior of composite samples," Arabian Journal of Geosciences, vol. 8, no. 7, pp. 4527-4539, 2015.

[17] Z. H. Zhao, W. M. Wang, and J. X. Yan, "Strain localization and failure evolution analysis of soft rock-coal-soft rock combination model," Journal of Applied Sciences, vol. 13, no. 7, pp. 1094-1099, 2013.

[18] L. Dou, C. Lu, and Z. Mu, "Rock burst tendency of coal-rock combinations sample," Journal of Mining \& Safety Engineering, vol. 23, pp. 43-46, 2006.

[19] Z. Zhao, W. Wang, L. Wang, and C. Dai, “Compression-shear strength criterion of coal-rock combination model considering interface effect," Tunnelling \& Underground Space Technology, vol. 47, pp. 193-199, 2015.

[20] Z. H. Zhao, W. M. Wang, C. Q. Dai, and J. X. Yan, "Failure characteristics of three-body model composed of rock and coal with different strength and stiffness," Transactions of Nonferrous Metals Society of China, vol. 24, pp. 1538-1546, 2014.
[21] J. Liu, C. Tang, W. Zhu, and T. Yang, "Effects of combination mode on mechanical properties and failure characteristics of the coal-rock combinations," Journal of China Coal Society, vol. 26, pp. 276-280, 2004.

[22] X. B. Deng, H. J. Hu, G. Xu, X. T. Li, and F. Y. Chen, "Numerical simulation for burst failure of two-body rock structure," Journal of Mining \& Safety Engineering, vol. 29, pp. 833-839, 2012.

[23] D. M. Guo, J. P. Zuo, Y. Zhang, and R. S. Yang, "Research on strength and failure mechanism of deep coal-rock combination bodies of different inclined angles," Rock \& Soil Mechanics, vol. 32, pp. 1333-1339, 2011.

[24] J. Li, Q. Qi, D. Mao, and Y. Wang, "Discussion on evaluation method of bursting liability wit composite model of coal and rock," Chinese Journal of Rock Mechanics \& Engineering, vol. 24, p. 4805, 2005.

[25] P. K. Kaiser and C. A. Tang, "Numerical simulation of damage accumulation and seismic energy release during brittle rock failure-part II: rib pillar collapse," International Journal of Rock Mechanics \& Mining Sciences, vol. 35, no. 2, pp. 123-134, 1998.

[26] V. A. Mansurov, "Prediction of rockbursts by analysis of induced seismicity data," International Journal of Rock Mechanics and Mining Sciences, vol. 38, no. 6, pp. 893-901, 2001.

[27] X. Wang, C. Lu, J. Xue et al., "Experimental research on rules of acoustic emission and microseismic effects of burst failure of compound coal-rock samples," Rock and Soil Mechanics, vol. 34, pp. 2569-2575, 2013.

[28] C. G Itasca, PFC (Particle Flow Code in 2 and 3 Dimensions), Version 5.0 (User's Manual), Minneapolis, 2014.

[29] D. O. Potyondy and P. A. Cundall, "A bonded-particle model for rock," International Journal of Rock Mechanics and Mining Sciences, vol. 41, no. 8, pp. 1329-1364, 2004.

[30] N. Cho, C. D. Martin, and D. C. Sego, "A clumped particle model for rock," International Journal of Rock Mechanics and Mining Sciences, vol. 44, no. 7, pp. 997-1010, 2007.

[31] P. A. Cundall, Numerical Experiments on Rough Joints in Shear Using a Bonded Particle Model, Springer, Heidelberg, Germany, 2000.

[32] D. O. Potyondy, "Simulating stress corrosion with a bondedparticle model for rock," International Journal of Rock Mechanics \& Mining Sciences, vol. 44, no. 2, pp. 677-691, 2007.

[33] Z. T. Bieniawski and M. J. Bernede, "Suggested methods for determining the uniaxial compressive strength and deformability of rock materials: part 1 . Suggested method for determining deformability of rock materials in uniaxial compression," International Journal of Rock Mechanics and Mining Sciences and Geomechanics Abstracts, vol. 16, no. 2, pp. 138-140, 1979.

[34] H. Zhang, D. Elsworth, and Z. Wan, "Failure response of composite rock-coal samples," Geomechanics and Geophysics for Geo-Energy and Geo-Resources, vol. 4, no. 2, pp. 175-192, 2018.

[35] H. Shimizu, S. Murata, and T. Ishida, "Distinct element analysis for rock failure considering ae events generated by the slip at crack surfaces," Journal of Acoustic Emission, vol. 27, pp. 194-211, 2009.

[36] H. Horii and S. Nemat-Nasser, "Compression-induced microcrack growth in brittle solids: axial splitting and shear failure," Journal of Geophysical Research Solid Earth, vol. 90, no. B4, pp. 3105-3125, 1985.

[37] D. Lockner, "The role of acoustic emission in the study of rock fracture," International Journal of Rock Mechanics and Mining 
Science and Geomechanics Abstracts, vol. 30, pp. 883-899, 1993.

[38] X. P. Zhang and L. N. Y. Wong, "Choosing a proper loading rate for bonded-particle model of intact rock," International Journal of Fracture, vol. 189, no. 2, pp. 163-179, 2014.

[39] E. Tuncay and N. Hasancebi, "The effect of length to diameter ratio of test specimens on the uniaxial compressive strength of rock," Bulletin of Engineering Geology and the Environment, vol. 68, no. 4, pp. 491-497, 2009.

[40] E. Hoek and E. T. Brown, Underground Excavations in Rock, Stephen Austin and Sons Ltd., London, UK, 1980.

[41] M. Bukowska, "Post-peak failure modulus in problems of mining geo-mechanics," Journal of Mining Science, vol. 49, no. 5, pp. 731-740, 2013.

[42] W. R. Wawersik and C. Fairhurst, "A study of brittle rock fracture in laboratory compression experiments," International Journal of Rock Mechanics and Mining Sciences and Geomechanics Abstracts, vol. 7, pp. 561-564, 1970.

[43] G. Pharr, W. Oliver, and F. Brotzen, "On the generality of the relationship among contact stiffness, contact area, and elastic modulus during indentation," Journal of Materials Research, vol. 7, no. 3, pp. 613-617, 1992.

[44] R. A. Toupin, "Saint-venant's principle," Archive for Rational Mechanics and Analysis, vol. 18, no. 2, pp. 83-96, 1965.

[45] Z. T. Bieniawski, "Mechanism of brittle fracture of rock: part II-experimental studies," International Journal of Rock Mechanics and Mining Sciences and Geomechanics Abstracts, vol. 4, no. 4, pp. 407-423, 1967.

[46] Z. T. Bieniawski, "Note on in situ testing of the strength of coal pillars," Journal of the South African Institute of Mining and Metallurgy, vol. May, pp. 455-465, 1968.

[47] N. G. W. Cook, "The failure of rock," International Journal of Rock Mechanics and Mining Sciences and Geomechanics Abstracts, vol. 2, no. 4, pp. 389-403, 1965. 


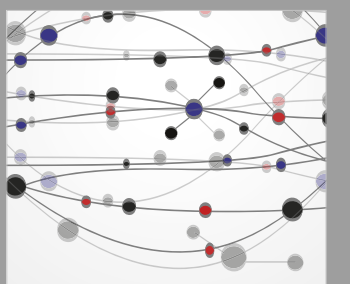

The Scientific World Journal
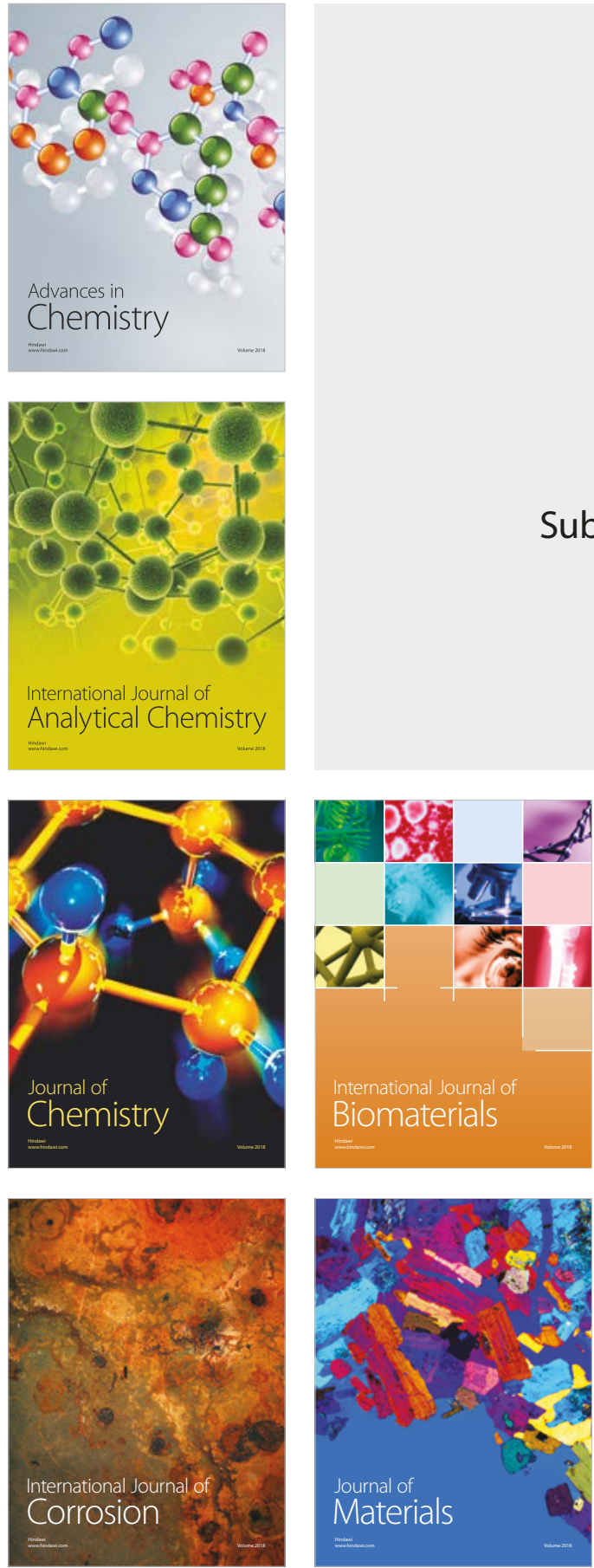

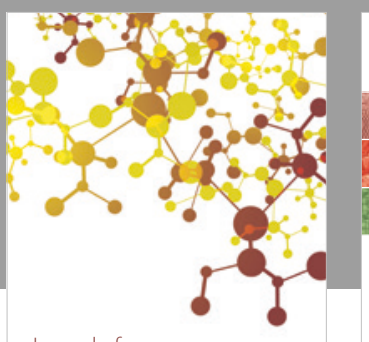

Journal of

Applied Chemistry
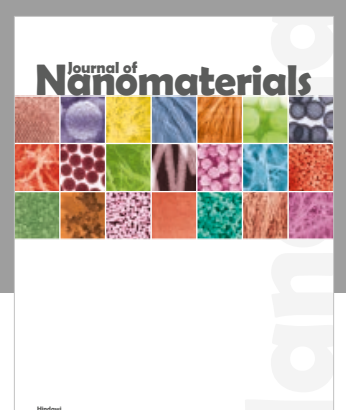

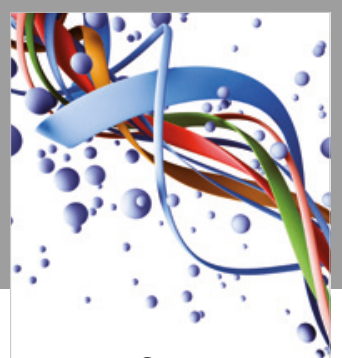

Scientifica

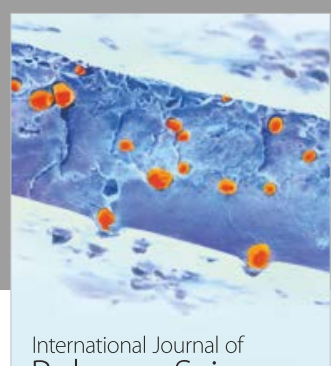

Polymer Science

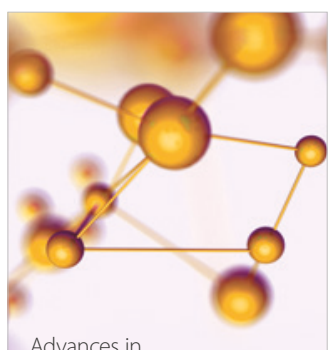

Physical Chemistry
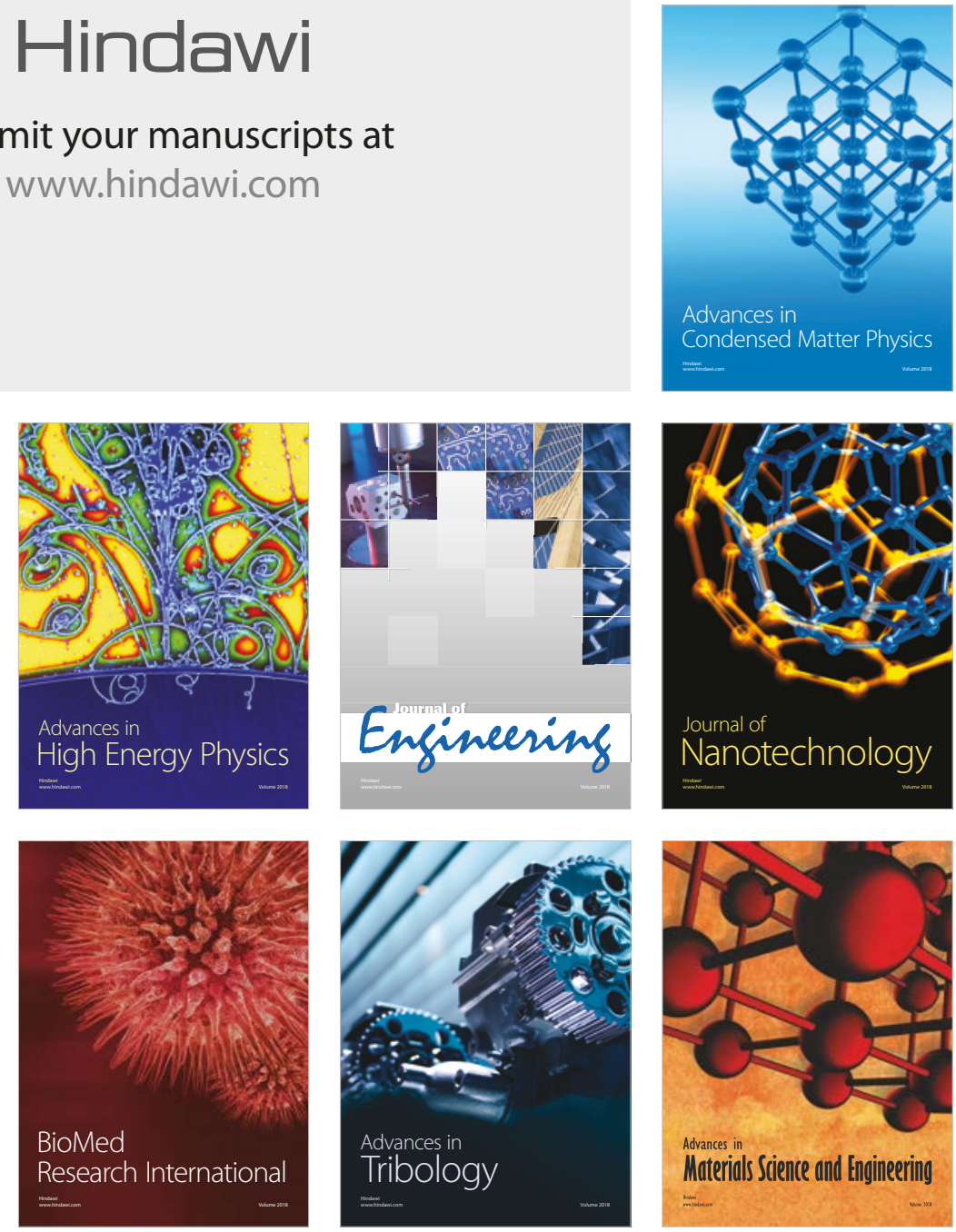